\title{
Unemployment and the smoothness of consumption in business cycle models
}

\author{
Liam Graham
}

First version : May 2002

This version : September 2002

\begin{abstract}
The permanent income hypothesis means that dynamic general equilibrium models fail to produce a hump-shaped response for consumption even if they do so for other variables. This article shows that the introduction of non-separable preferences and unemployment can solve this problem.
\end{abstract}

JEL classification: E24, E32.

Keywords: Consumption smoothing, unemployment, business cycles, non-separable preferences

* Liam Graham: Department of Economics, Birkbeck College, 7-15 Gresse Street, London, W1T 1LL, UK. Email: lgraham@econ.bbk.ac.uk. Phone: +44 207631 6428. Fax: +44 20 76316416. 


\section{Introduction}

The permanent income hypothesis implies that consumption acts as a jump variable, responding immediately to new information. However a number of studies (e.g. Campbell and Deaton (1989)) suggest that instead consumption displays a gradual hump-shaped response, which business cycle models have difficulty reproducing. In this article I show that a real business cycle model can produce such a hump-shaped response in consumption if modified in two ways. Firstly, by introducing unemployment into the model. Secondly by using preferences which are additively non-separable in consumption and leisure so that consumption depends on employment status. Then if employment responds gradually to a shock, so will aggregate consumption. The gradual response of employment could result from any number of adjustment process or costs in general equilibrium, so this mechanism is applicable to a wide range of dynamic general equilibrium models.

Let me consider the two modifications in more detail. I introduce unemployment by a slightly modified version of Hansen's (1984) indivisible labour model. This posits that instead of a continuously supplying labour, households face the choice of either working a fixed shift or not working at all. A lottery (comparable to unemployment insurance) determines whether households work or not and efficient risk sharing across this lottery implies that the marginal utility of consumption of the two groups is equalised. If utility is separable in consumption and labour, it follows that the consumption of the two groups is also equal, with the unappealing result that there is "involuntary employment": the unemployed are happier than the employed since they have the same consumption but more leisure.

Basu and Kimball (2000) assert that "one of the greatest recommendations of the assumption of additive separability between consumption and labor has been simplicity". When applied to the form of preferences necessary for balanced growth in dynamic general equilibrium models (see King, Plosser and Rebelo (1988)) non-separability implies a value of the coefficient of relative risk aversion greater than unity. This is supported by empirical 
estimates of the coefficient of relative risk aversion (surveyed by Kocherlakota (1996)) which consistently obtain values greater than unity.

Non-separable preferences mean that the marginal utility of consumption is higher for employed workers than for unemployed workers, so equalising marginal utilities across Hansen's lottery will mean a higher level of consumption is allocated to the employed. This implication finds considerable support in the literature - for example Cochrane (1991) reports a fall in consumption growth of 24-27\%, Browning and Crossley (2001) a mean fall in consumption of $14 \%$ on unemployment.

\section{The model}

I adapt the standard RBC model of King, Plosser and Rebelo (1988) to include indivisible labour ${ }^{1}$. The result of this paper depends on their being a gradual response of employment to a shock which could be caused by a wide range of phenomena. For the purposes of this exposition I choose employment adjustment costs as the mechanism to induce this gradual response of employment.

A representative agent with rational expectations consumes, supplies labour and faces the problem:

$$
\max _{\left\{c_{t+j}, \eta_{+j}\right\}_{j=0}^{\infty}} E_{t} \sum_{i=0}^{\infty} \beta^{i} U\left(c_{t+i}, n_{t+i}\right)
$$

subject to $\quad y_{t}=a_{t} k_{t}^{1-\alpha} n_{t}^{\alpha}-g\left(n_{t}, n_{t-1}\right)$

$$
\begin{aligned}
& y_{t}=c_{t}+i_{t} \\
& k_{t+1}=i_{t}+(1-\delta) k_{t}
\end{aligned}
$$

Where $U\left(c_{t}, n_{t}\right)$ is the utility of the representative agent, $\mathrm{c}_{\mathrm{t}}$ consumption, $\mathrm{n}_{\mathrm{t}}$ employment, $\mathrm{y}_{\mathrm{t}}$ output, $\mathrm{k}_{\mathrm{t}}$ the capital stock, $\mathrm{a}_{\mathrm{t}}$ the level of technology, $\mathrm{i}_{\mathrm{t}}$ investment and $\delta$ the rate of

\footnotetext{
${ }^{1}$ I follow King and Rebelo's (1999) extension of the indivisible labour model of Hansen (1984)
} 
depreciation. The term $g\left(n_{t}, n_{t-1}\right)$ represents employment adjustment costs and I choose a simple functional form:

$$
g\left(n_{t}, n_{t-1}\right)=\alpha_{n}\left(\frac{n_{t}}{n_{t-1}}\right)^{\varsigma}
$$

I use the following individual utility function after King, Plosser and Rebelo (1988):

$$
\begin{aligned}
& u\left(c_{t}, n_{t}\right)=\log c_{t}+\theta \log v\left(n_{t}\right) \text { for } \sigma=1 \\
& u\left(c_{t}, n_{t}\right)=\frac{1}{1-\sigma} c_{t}^{1-\sigma} v\left(n_{t}\right) \text { for } \sigma \neq 1
\end{aligned}
$$

This implies that the relative consumption of employed workers and unemployed workers (denoted by superscripts 1 and 2 respectively) is given by:

$$
\frac{c_{t}^{1}}{c_{t}^{2}}=\left(\frac{v^{2}}{v^{1}}\right)^{\frac{\sigma-1}{\sigma}}
$$

where $v^{1}=v(h), v^{2}=v(0)$ and $\mathrm{h}$ is the shift length. Households prefer leisure to work so $v^{2}$ $>v^{1}$ then if $\sigma>1$ the employed will consume more than the unemployed.

To calibrate the model I choose $\sigma$, the coefficient of relative risk aversion to be 2 , implying that the unemployed consume $45 \%$ less than the employed. This is higher than found in the data, but given the simplicity of the Hansen lottery some discrepancy would be expected. Basu and Kimball (2000), referring to a similar point, write "it is likely to be much easier to modify a non-separable model to moderate the drop in consumption.... than to get a significant drop... out of a model with additive separability". I choose the coefficient on the employment cost term in the linearised system to be 0.2 , which is in line with work by Shapiro (1986). I follow King and Rebelo (1999) for all other parameters.

\section{Results}

Figure 1 shows the response of the model economy to a persistent $1 \%$ shock in the growth rate of technology. The hump-shaped path of employment results from employment adjustment costs, and one can see the intertemporal substitution of labour characteristic of RBC models. The path of aggregate consumption shows a hump-shape too, and seems 
inconsistent with the real interest rate: the latter is above its steady state value for around 15 quarters which should imply consumption is rising during this period, whereas aggregate consumption rises for only 3 periods after the shock and falls gradually thereafter.

This apparent inconsistency is resolved by looking at the series for individual consumption which can be backed-out by noting that aggregate consumption is related to individual consumption by:

$$
c_{t}=n_{t} c_{t}^{1}+\left(1-n_{t}\right) c_{t}^{2}
$$

The resulting series is shown in figure 1. This has the same form as a consumption series from a standard RBC model (see King, Plosser and Rebelo (1988)). Individual consumption is much smoother than aggregate, and is consistent with the real interest rate and the permanent income hypothesis. The effect of intertemporal substitution of labour can be observed in period 20 when aggregate consumption falls below individual.

\section{Conclusion}

This paper modifies a baseline real business cycle model by introducing unemployment and non-separable preferences. Calibrating the model so that the employed consume more than the unemployed links aggregate consumption and employment. If employment responds gradually to a shock, so too will aggregate consumption. This link is not reliant on the assumptions of a technology shock and employment adjustment costs used in the exposition. The gradual response of employment could arise within a more sophisticated model of the labour market or, in general, from any adjustment process which leads to output responding gradually. These modifications could be applied to a wide range of dynamic general equilibrium models (see Graham (2002) allowing them to produce more realistic responses for consumption.

\section{Acknowledgements}

With thanks to Pedro Bacao, Martin Christiansen, Jean Imbs and Stephen Wright for useful comments, and special thanks to John Driffill my $\mathrm{PhD}$ supervisor. An anonymous referee 
provided invaluable comments which greatly improved this paper. Naturally any errors remain my own. I am grateful to the UK's Economic and Social Science Research Council for support for the research project of which this paper is a part. 
Figure 1 : Impulse Response of the Model Economy to a persistent technology shock

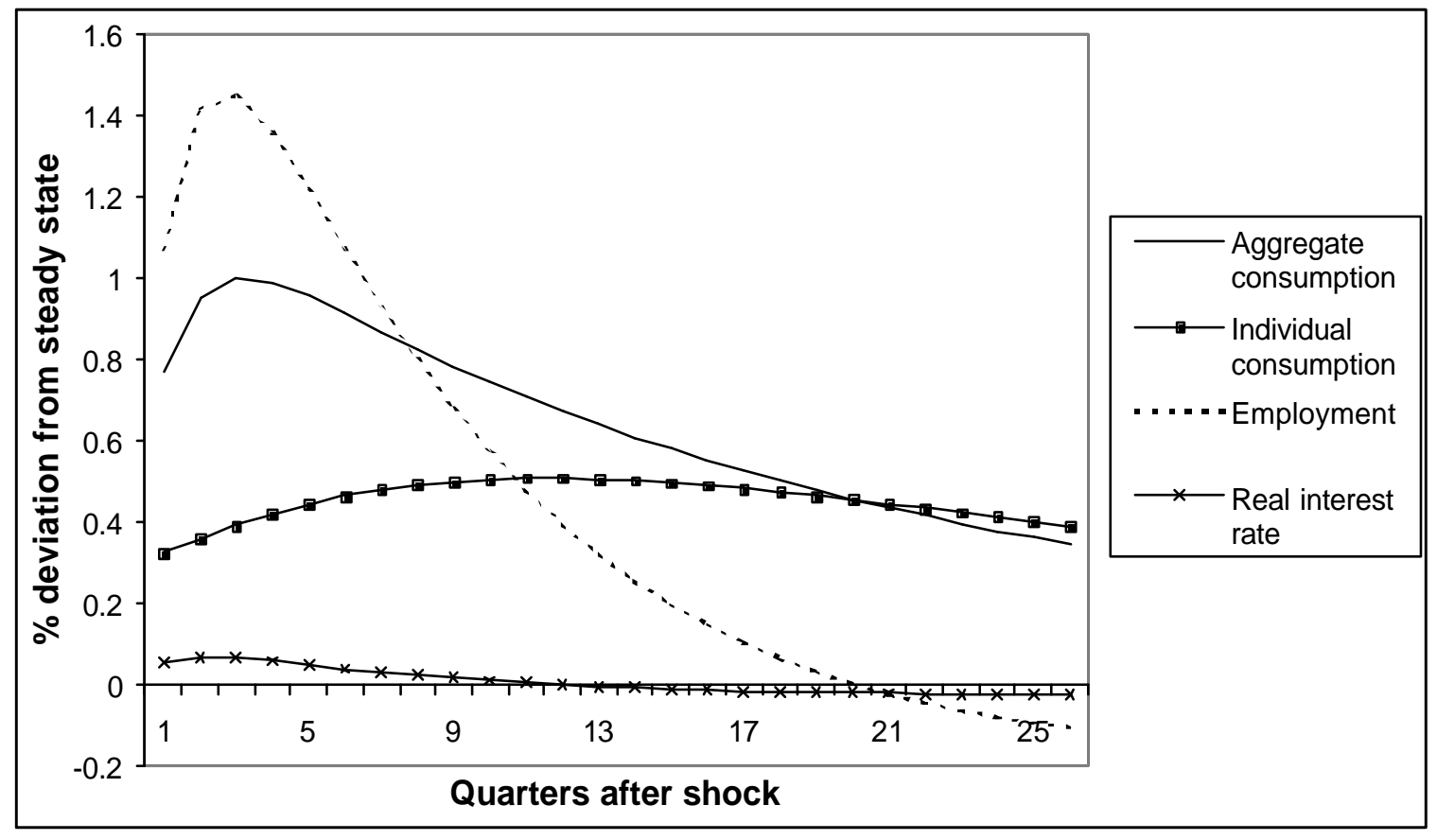




\section{References}

Basu, S. and M. Kimball, 2000, Long-run labour supply and the Elasticity of Intertemporal Substitution for Consumption, Working paper, University of Michigan

Browning, M. and T. Crossley, 2001, Unemployment insurance benefit levels and consumption changes, Journal of Public Economics, 80, 1-23

Campbell, J. and A. Deaton, 1989, Why is Consumption So Smooth?, Review of Economic Studies, 56, 3, 357-373

Cochrane, J., 1991, A Simple Test of Consumption Insurance, Journal of Political Economy, 99, 5, 957-976

Graham, L., 2002, Output Dynamics in a Monetary Model, Working paper, Birkbeck College, University of London

Hansen, G., 1984, Indivisible labour and the business cycle, Journal of Monetary Economics, $16,309-327$

King, R., C. Plosser and S. Rebelo, 1988, Production, Growth and Business Cycles I: The basic neo-classical model, Journal of Monetary Economics, 2, 195-232

King, R. and S. Rebelo, 1999, Resuscitating real business cycles, in Taylor, John B. and Michael Woodford (eds.), "Handbook of macroeconomics", Amsterdam. Oxford. Elsevier, 1999

Kocherlakota, N., 1996, The equity premium : it's still a puzzle, Journal of Economic Literature, 34, 1, 42-71

Shapiro, M., 1986, The dynamic demand for capital and labour, Quarterly Journal of Economics, 101, 3, 513-542 